\title{
A Pilot Study to assess the Impact of structured Diet and Exercise Counselling on Obesity and Quality of Life Measures in South Carolina
}

\author{
H. Cooney ${ }^{1}$, N. Madhusudan ${ }^{1}$ and N. S. Murali ${ }^{2}$, MD \\ ${ }^{1}$ University of Birmingham, United Kingdom B15 2 TT and ${ }^{2}$ Gastroenterology Associates of South Carolina, \\ Orangeburg, America
}

Obesity is a pervasive problem in America, especially in South Carolina, with $33.9 \%$ of the population overweight and $32.6 \%$ obese ${ }^{(1)}$. Obesity is associated with a poor quality of life (QOL), as shown by the Medical Outcomes Study Short Form (SF questionnaires) ${ }^{(2)}$.

This study aimed to assess whether structured counselling on healthy diet and exercise choices in patients with a body mass index (BMI) over $25 \mathrm{~kg} / \mathrm{m}^{2}$ had an impact on their QOL, understanding the benefits of healthy diet and exercise choices (DAEC) and BMI.

In this prospective pilot study, 104 patients were recruited at a gastroenterology centre in South Carolina. At the initial consultation, their QOL and knowledge of DAEC were assessed using the SF-12, and a structured 'diet and exercise' questionnaire (DAEQ). Their BMI was recorded, and categorized according to the World Health Organisation International Classification of Weight According to BMI (Overweight, Obese class I, II or III) ${ }^{(3)}$. They were counselled for 40 minutes on portion sizes, healthy meal choices and the importance of regular exercise. Their comprehension was verified by information recall. Written guidelines were supplied, reinforcing this information. These directives were based on guidance from the Center for Nutrition Policy and Promotion $^{(4)}$. The follow-up period was two months, in which patients received two phone calls to monitor their progress, SF-12 and DAEQ scores, and BMI.

The results before and after structured counselling are summarized in the table below. The Student's $T$-Test was used to calculate $p$ values $(*$ for $p \leqslant 0.05$ and $* *$ for $p \leqslant 0.01)$.

\begin{tabular}{|c|c|c|c|c|c|c|c|c|}
\hline & \multicolumn{2}{|c|}{ Mean (SD) PCS-12 } & \multicolumn{2}{|c|}{ Mean (sD) MCS-12 } & \multicolumn{2}{|c|}{ Mean (SD) DAEQ Score } & \multicolumn{2}{|c|}{ Mean (sD) BMI $\left(\mathrm{kg} / \mathrm{m}^{2}\right)$} \\
\hline & Before & After & Before & After & Before & After & Before & After \\
\hline Overweight $(n=20)$ & $41.98(10.48)$ & $44.02(10.40)$ & $49.37(10.32)$ & $51.72(9.75)$ & $9.15(4.02)$ & $10.10(4.41)$ & $28.26(1.30)$ & $27.94(1.47)$ \\
\hline Obese Class I $(n=35)$ & $43.48(9.46)$ & $42.77(11.09)$ & $49.23(10.46)$ & $52.61(9.00)^{* *}$ & $8.63(3.16)$ & $8.86(2.95)$ & $32.42(1.43)$ & $32.54(2.61)$ \\
\hline Obese Class II $(n=24)$ & $40.72(11.18)$ & $43.79(10.53)^{* *}$ & $54.53(7.85)$ & $47.12(9.22)$ & $9.71(3.77)$ & $9.04(4.05)$ & $37.10(1.42)$ & $36.45(1.87)^{* *}$ \\
\hline Obese Class III $(n=25)$ & $36.42(8.36)$ & $36.38(10.15)$ & $46.92(9.78)$ & $48.82(10.90)$ & $11.50(0.36)$ & $8.54(0.30)$ & $44.71(4.45)$ & $43.49(5.72)^{*}$ \\
\hline
\end{tabular}

This study highlights the benefits of regular counselling, as an intervention for obesity management. With further follow-up, there is potential for greater improvement in results. There is an opportunity for physicians to motivate patients to take responsibility for their own physical and mental health, and prevent future co-morbidities through regular counseling.

1. US Census Bureau. Statistical Abstract of the United States 2012. Section 3 Health and Nutrition. Available from: https://www.census.gov/prod/ $2011 \mathrm{pubs} / 12 \mathrm{statab} / \mathrm{h}$ ealth.pdf. Last accessed August 2013.

2. Wee CC, Davis RB, Hamel MB (2008) Comparing the SF-12 and SF-36 health status questionnaires in patients with and without obesity. Health Oual Life Outcomes 6, 11

3. World Health Organisation. BMI classification. Available from: http://apps.who.int/bmi/index.jsp?introPage=intro_3.html

4. Center for Nutrition Policy and Promotion. Improving the nutrition and well-being of Americans. Available from: http://www.cnpp.usda.gov/. Last accessed August 2013. 